\title{
ON BALANCING QUATERNIONS AND LUCAS-BALANCING QUATERNIONS
}

\author{
Dorota Bród \\ Rzeszow University of Technology \\ Faculty of Mathematics and Applied Physics \\ al. Powstańców Warszawy 12, 35-959 Rzeszów, Poland \\ e-mail: dorotab@prz.edu.pl
}

\begin{abstract}
In this paper we define and study balancing quaternions and Lucasbalancing quaternions. We give the generating functions, matrix generators and Binet formulas for these numbers. Moreover, the well-known properties e.g. Catalan, d' Ocagne identities have been obtained for these quaternions.

Keywords: balancing number, Lucas-balancing number, quaternion, Binet formula, generating function.
\end{abstract}

2010 Mathematics Subject Classification: 11R52, $11 B 37$.

\section{REFERENCES}

[1] A. Behera and G.K. Panda, On the square roots of triangular numbers, Fibonacci Quart. 37 (1999) 98-105.

[2] P. Catarino, H. Campos and P. Vasco, On some identities for balancing and cobalancing numbers, Ann. Math. Inform. 45 (2015) 11-24.

http://ami.ektf.hu

[3] C.B. Çimen, A. İpek, On Pell Quaternions and Pell-Lucas Quaternions, Adv. Appl. Clifford Alg. 26 (2016) 39-51.

doi:10.1007/s00006-015-0571-8

[4] A.F. Horadam, Complex Fibonacci Numbers and Fibonacci Quaternions, Amer. Math. Monthly 70 (1963) 289-291.

doi: $10.2307 / 2313129$

[5] A. İpek, On $(p, q)$-Fibonacci quaternions and their Binet formulas, generating functions and certain binomial sums, Adv. Appl. Clifford Alg. 27 (2017) 1343-1351. doi:10.1007/s00006-016-0704-8 
[6] G.K. Panda, Some fascinating properties of balancing numbers, Proc. Eleventh Internat. Conference on Fibonacci Numbers and Their Applications, Cong. Numerantium 194 (2009) 185-189.

[7] G.K. Panda and P.K. Ray, Cobalancing numbers and cobalancers, Int. J. Math. and Math. Sci. 8 (2005) 1189-1200. doi:10.1155/IJMMS.2005.1189

[8] B.K. Patel and P.K. Ray, On the properties of $(p, q)$-Fibonacci and $(p, q)$-Lucas quaternions, Math. Reports 21 (2019) 15-25.

[9] P.K. Ray, Certain Matrices Associated with Balancing and Lucas-balancing Numbers, Matematika 28 (2012) 15-22.

[10] P.K. Ray and J. Sahu, Generating functions for certain balancing and Lucasbalancing numbers, Palest. J. Math. 5 (2016) 122-129.

[11] A. Szynal-Liana and I. Włoch, A note on Jacobsthal quaternions, Adv. Appl. Clifford Alg. 26 (2016) 441-447.

doi:10.1007/s00006-015-0622-1

[12] A. Szynal-Liana and I. Włoch, The Pell Quaternions and the Pell Octonions, Adv. Appl. Clifford Alg. 26 (2016) 435-440. doi: $10.1007 / \mathrm{s} 00006-015-0570-9$

[13] J.P. Ward, Quaternions and Cayley Numbers: Algebra and Applications (Kluwer Academic Publishers, London, 1997).

Received 21 May 2019

Revised 28 February 2020

Accepted 8 May 2020 